\title{
Correlation of serum soluble endoglin to the severity of pre-eclampsia and its effect on the pregnancy outcome
}

\section{Tamer Mamdouh Abd El-Dayem ${ }^{1}$, Ahmed Samy Elagwany ${ }^{1}$, Mohammed Yosry Khamis ${ }^{1}$, Eman Soliman Kamha ${ }^{2}$, Ahmed Mohammed Mohammed Hassan ${ }^{1,2}$}

\author{
${ }^{1}$ Department of Obstetrics and Gynecology, Faculty of Medicine, Alexandria University, Egypt \\ ${ }^{2}$ Department of Medical Biochemistry Faculty of Medicine, Alexandria University, Egypt
}

Received: 23 February 2016

Revised: 24 February 2016

Accepted: 18 March 2016

\author{
*Correspondence: \\ Dr. Ahmed Samy Elagwany, \\ E-mail: ahmedsamyagwany@gmail.com
}

Copyright: (c) the author(s), publisher and licensee Medip Academy. This is an open-access article distributed under the terms of the Creative Commons Attribution Non-Commercial License, which permits unrestricted non-commercial use, distribution, and reproduction in any medium, provided the original work is properly cited.

\begin{abstract}
Background: Preeclampsia is a major obstetric problem and a significant source of maternal and neonatal morbidity and mortality. Preeclampsia is associated with increased risks of placental abruption, acute renal failure, cerebrovascular and cardiovascular complications, disseminated intravascular coagulation, and maternal death. Consequently, early diagnosis of preeclampsia and close observation are imperative. In these cases of preeclampsia, combination of Doppler flowmetry and circulating angiogenic factors levels are recorded. Stepan et al examined endoglin, a cell-surface co-receptor for transforming growth factor in patients with Doppler flow patterns of preeclampsia at 19-24 weeks. Soluble endoglin levels were elevated in second trimester pregnancies with abnormal uterine perfusion in women who experienced preeclampsia. The aim of this study was to test if there is correlation between the level of serum endoglin in pregnant women with severe preeclampsia to the maternal and fetal outcome.

Methods: This study was conducted on a group of 90 pregnant women attended to the Antenatal clinic and selected from the preeclampsia unit of EL- Shatby Maternity University Hospital, The selected patients were subdivided in two groups. Group A (control group): 30 cases of normotensive pregnant ladies. Group B (case group): 60 cases of severe preeclamptic pregnant ladies. Routine investigations, maternal serum soluble endoglin and ultrasound results were analysed and compared for both groups.

Results: Significant correlation was found between severe preeclampsia and high level soluble endoglin. Significant correlation was found between high level of soluble endoglin and the occurrence of IUGR among the severe preeclamptic patients. Positive correlation was found between serum level of soluble endoglin and uterine artery PI and uterine artery RI, the higher the serum level of soluble endoglin the higher the uterine artery pulsatility and resistance index. Significant correlation was found between high level of soluble endoglin and the occurrence of specific complications, the higher the level of soluble endoglin the higher the risk of exposure to preeclampsia complications as the occurrence of eclamptic fits, the development of HELLP syndrome, the admission to the ICU, the admission of the baby to the NICU, and the fetal death.

Conclusions: From our study, it is evident that serum endoglin rises during normal as well as preeclamptic pregnancy and that the rise in preeclampsia is much higher, the rise in endoglin levels may occur as early as the first trimester in pregnancies which later develop preeclampsia. Hence, used alone or in combination with uterine artery Doppler flowmetry, the measurement of soluble serum endoglin has the potential for use as a predictive clinical test for preeclampsia risk assessment and could potentially improve the outcome of pregnancy.
\end{abstract}

Keywords: Serum soluble endoglin, Pre-eclampsia, Pregnancy outcome 


\section{INTRODUCTION}

Pre-eclampsia (PE) a pregnancy-specific syndrome characterized by new onset hypertension and proteinuria, is a considerable obstetric problem and a significant source of maternal and neonatal morbidity and mortality. ${ }^{1}$ Although preeclampsia and related hypertensive disorders of pregnancy continue to affect approximately $8 \%$ of all pregnancies, the incidence of preeclampsia has continued to increase in recent years. ${ }^{2,3}$ Moreover, it has recently been recognized that women who endure preeclampsia are at a greater risk for cardiovascular disease than non-pre-eclamptic women. ${ }^{4}$ Despite thorough characterization of the pre-eclamptic syndrome and a suite of contributing circulating factors, the mechanisms underlying the pathogenesis of this troubling condition remain nebulous. ${ }^{1,5}$ Interestingly, it has been proposed that not only the increased circulating factors are responsible for much of the pre-eclamptic syndrome, but they may also predispose the maternal cardiovascular system to subsequent endothelial dysfunction as the mother ages. ${ }^{6}$

Preeclampsia develops during $2^{\text {nd }}$ half of pregnancy and remits after delivery or termination of the pregnancy, suggesting that the placenta is a central culprit in the disease. The foremost hypothesis regarding the initiating event in preeclampsia is postulated to be reduced placental perfusion that, in turn, leads to widespread dysfunction of the maternal vascular endothelium. ${ }^{1}$ Numerous other factors including genetic immunological, behavioral, and environmental influences have been implicated in the pathogenesis of preeclampsia. ${ }^{1}$

Although the pathophysiology of preeclampsia remains undefined, placental ischemia/hypoxia is widely regarded as a key factor. ${ }^{5,7}$ Inadequate trophoblast invasion leads to incomplete remodeling of the uterine spiral arteries is considered to be a primary cause of placental ischemia. ${ }^{8}$ Thus the poorly perfused and hypoxic placenta is thought to synthesize and release increased amounts of vasoactive factors such as soluble fms-like tyrosine kinase-1 (sFlt-1), cytokines, and possibly the angiotensin II (ANG II) type 1 receptor autoantibodies (AT1-AA). ${ }^{8,9}$

Perhaps the most prominent molecule postulated to play a key role in the pathogenesis of preeclampsia is sFlt-1. Several lines of evidence ${ }^{10,11}$ support the hypothesis that the ischemic placenta contributes to endothelial cell dysfunction in the maternal vasculature by inducing an alteration in the balance of circulating levels of angiogenic/antiangiogenic factors such as vascular endothelial growth factor (VEGF), placental growth factor (PlGF), and sFlt-1. Although recent data suggest that circulating sFlt-1 concentrations may predict the clinical onset of preeclamptic symptoms. ${ }^{10,12}$ Several studies indicate that placental hypoxia and poor placental perfusion may initiate this imbalance of angiogenic factors. ${ }^{13}$ These data suggest that Soluble Endoglin
(sEng) plays an important role in the pathophysiology of PE.

Both sFlt-1 and sEng have antiangiogenic effects, and are considered endogenous antiangiogenic factors in humans. sFlt-1 binds toVEGF and PIGF $^{14}$ and blocks their angiogenic actions to vascular tissues. . Excess amounts of sFlt- 1 and sEng derived from the placenta may offset VEGF, PIGF, and Transforming growth factor beta 1 (TGF $\beta 1$ ) bioactivities, impair maternal vascular endothelial function, and induce glomerular endotheliosis in PE. ${ }^{9,15}$ The harmful effects produced by sEng and sFlt1 are believed to be a major component in the pathogenesis of PE. $^{15}$

Soluble endoglin concentrations correlate to the occurrence and severity of preeclampsia and resolve following delivery. Furthermore, sEng levels have been shown to be significantly higher 3 months prior to the development of proteinuria or hypertension, whereas the sFlt1: PIGF ratio increases closer to disease onset. ${ }^{16,17}$

Pregnancies in which there is intrauterine growth restriction unrelated to preeclampsia also demonstrate elevated levels of sEng, suggesting this marker may not be specific for preeclampsia but rather for a dysfunctional placenta. Animal model studies demonstrate that induction of the hepatic and renal complications that occur with HELLP syndrome transpire after administration of sEng and sFlt-1, suggesting that the two proteins may have a synergistic effect responsible for the more severe cases of PE. ${ }^{18}$

In the past few years, a role for the novel angiostatic factor endoglin (CD105) in pre-eclampsia has been proposed. ${ }^{18}$ Endoglin is a co-receptor for the transforming growth factor- $\beta$ (TGF- $\beta$ ) isoforms, TGF- $\beta 1$ and TGF- $\beta 3$, is highly expressed in endothelial cells and syncytiotrophoblasts, and modulates the actions of TGF$\beta 1$ and TGF- $\beta 3,{ }^{19}$ Endoglin regulates the activity of endothelial nitric oxide synthase (eNOS) and, subsequently, local vascular tone by inhibiting TGF- $\beta 1$ binding and signalling in endothelial cells, blocking TGF$\beta 1$-mediated activation of eNOS and inhibiting NOSdependent vasodilation, suggesting the involvement of endoglin in both cardiovascular development and vascular homeostasis. ${ }^{20}$

The aim of this study was to correlate the level of serum endoglin in pregnant women with severe preeclampsia to the maternal and fetal outcome.

\section{Patients}

This study which was a case control was conducted on a group of 90 pregnant women attended to the Antenatal clinic and selected from the preeclampsia unit of ELShatby Maternity University Hospital. 
Pregnant Women with pre-eclampsia diagnosed and classified according to the strict criteria recommended by The American College of Obstetricians and Gynecologists (ACOG). ${ }^{21}$

Severe pre-eclampsia will be diagnosed by: A systolic/diastolic blood pressure $\geq 160 \mathrm{~mm} \mathrm{Hg} / 110 \mathrm{~mm}$ $\mathrm{Hg}$, Either a urine dipstick showing $3+$ or $4+$ in a random urine sample or $>5.0 \mathrm{~g}$ protein $/ 24 \mathrm{~h}$, Elevated serum creatinine or blood urea above $7 \mathrm{mg} / \mathrm{dl}$,Pulmonary oedema, Oliguria $(<500 \mathrm{ml} / 24 \mathrm{~h})$, Fetal growth restriction : estimated fetal weight below 5 th percentile for age, oligohydramnios, symptoms suggesting significant impending eclampsia (headache, visual disturbance, or epigastric or right upper quadrant pain), HELLP syndrome (hemolytic anemia, elevated liver enzymes, and a low platelet count) patients with Multiple gestation, Diabetes mellitus, chronic hypertension, chronic renal failure, premature rupture of the membrane, active labour or polyhydramnios were excluded.

The patients were divided into 2 groups: Group (A): control group, 30 normotensive pregnant ladies. Group (B): 60 severe pre-eclamptic pregnant ladies.

\section{METHODS}

All patients who participated in this study were subjected to complete history taking including obstetric history of previous deliveries (number, type, complications, history of abortion), general examination (blood pressure, pulse, weight, height), Abdominal examination including fundal level and symphysio-fundal length, routine investigations: Complete blood count, serum level of aspartate aminotransferase and alanine aminotransferase, urea, createnine, uric acid, prothrombin time (PT), partial thromboplastin time (PTT), INR and estimation of serum level of soluble endoglin by ELISA method. The Blood samples were taken and kept at room temperature for 30 minutes to allow the blood to clot .they were then centrifuged at $1000 \mathrm{~g}$ for 15 minutes to separate the serum, which was then stored at $-80^{\circ} \mathrm{C}$ until assayed.

Obstetric ultrasonography for: Fetal biometry, Biophysical profile, Uterine artery Doppler, Umbilical artery doppler and Middle cerebral artery doppler to evaluate degree of possible placental insufficiency and brain sparing effect.

Follow up till delivery: Recording mode of delivery, Maternal outcome: Maternal morbidity eg. HELLP, admission to ICU, eclamptic fits, heart failure , renal failure or intracranial hemorrhage Maternal mortality. Fetal outcome: Birth weight, Apgar scoring at 1 and 5 minutes, Admission to NICU.

\section{Statistical analysis of the data ${ }^{22}$}

Data were fed to the computer and analyzed using IBM SPSS software package version 20.0. ${ }^{23}$ Qualitative data were described using number and percent. Quantitative data were described using range (minimum and maximum), mean, standard deviation and median. Comparison between different groups regarding categorical variables was tested using Chi-square test.

\section{RESULTS}

Table 1: Demographic findings.

\begin{tabular}{|lll|c|}
\hline & $\begin{array}{l}\text { Severe } \\
\text { preeclampsia }\end{array}$ & $\begin{array}{l}\text { Control } \\
\text { group }\end{array}$ & P value \\
\hline Age & $27.68 \pm 4.80$ & $28.47 \pm 5.93$ & 0.502 \\
\hline $\begin{array}{l}\text { Parity } \\
\text { Primigravida }\end{array}$ & $50 \%$ & $40 \%$ & \\
Mutigravida & $50 \%$ & $60 \%$ & 0.370 \\
\hline $\begin{array}{l}\text { Gestational } \\
\text { age }\end{array}$ & $32.18 \pm 3.33$ & $25.39 \pm 5.12$ & $<0.001^{*}$ \\
\hline Systolic BP & $162.67 \pm 14.71$ & $107.67 \pm 10.73$ & $<0.001^{*}$ \\
\hline Diastolic BP & $111.67 \pm 13.55$ & $74.67 \pm 5.71$ & $<0.001^{*}$ \\
\hline
\end{tabular}

* Statistically significant at $\mathrm{p} \leq 0.05$.

Table 2: Routine investigations.

\begin{tabular}{|llll|}
\hline & $\begin{array}{l}\text { Severe } \\
\text { preeclampsia }\end{array}$ & $\begin{array}{l}\text { Control } \\
\text { group }\end{array}$ & P value \\
\hline $\begin{array}{l}\text { Urine } \\
\text { albumin } \\
\mathbf{+ 3}\end{array}$ & $51.7 \%$ & $0 \%$ & $<0.001^{*}$ \\
\hline ALT & $46.82 \pm 57.78$ & $26.43 \pm 4.61$ & $<0.001^{*}$ \\
\hline AST & $51.08 \pm 64.03$ & $28.70 \pm 4.43$ & $<0.001^{*}$ \\
\hline $\begin{array}{l}\text { Platelet } \\
\text { count }\end{array}$ & $185.68 \pm 61.31$ & $232.0 \pm 52.88$ & $<0.001^{*}$ \\
\hline Uric acid & $6.34 \pm 1.21$ & $5.42 \pm 0.76$ & $<0.001^{*}$ \\
\hline Creatinine & $0.81 \pm 0.21$ & $0.60 \pm 0.11$ & $<0.001^{*}$ \\
\hline
\end{tabular}

*Statistically significant at $\mathrm{p} \leq 0.05$, ALT Alanine transaminase, AST aspartate aminotransferase.

Table 3: Obstetric and Doppler ultrasound.

\begin{tabular}{|llll|}
\hline & $\begin{array}{l}\text { Severe } \\
\text { preeclampsia }\end{array}$ & Control group & P value \\
\hline EFW & $1215.7 \pm 781.2$ & $1553.5 \pm 618.5$ & $0.042^{*}$ \\
\hline AFI & $9.62 \pm 1.81$ & $14.03 \pm 1.0$ & $<0.001$ \\
\hline $\begin{array}{l}\text { Present } \\
\text { Ut A } \\
\text { notch }\end{array}$ & $63.3 \%$ & $0 \%$ & $<0.001^{*}$ \\
\hline Ut A PI & $1.06 \pm 0.28$ & $0.73 \pm 0.06$ & $<0.001^{*}$ \\
\hline Ut A RI & $0.54 \pm 0.11$ & $0.39 \pm 0.04$ & $<0.001^{*}$ \\
\hline $\begin{array}{l}\text { Um A } \\
\text { S/D }\end{array}$ & $3.90 \pm 0.98$ & $3.08 \pm 0.72$ & $<0.001^{*}$ \\
\hline
\end{tabular}

*Statistically significant at $\mathrm{p} \leq 0.05$, EFW estimated fetal weight, AFI amniotic fluid index, Ut A uterine artery, PI pulsatility index, RI resistance index, Um A umbilical artery, $\mathrm{S} / \mathrm{D}$ systolic/Diastolic ratio.

Sixty women with severe preeclampsia were recruited for the study in addition thirty women with normal pregnancy were used as control as shown in table 1 no 
significant difference was found between groups in terms of maternal age and parity. Significant difference was found between the groups according to gestational age, systolic and diastolic blood pressure was significantly higher in the severe preeclampsia group than control group $(\mathrm{P}<0.001)$.
Table 4: Soluble endoglin level.

\begin{tabular}{|c|c|c|c|c|}
\hline $\begin{array}{l}\text { Soluble } \\
\text { endoglin }\end{array}$ & $\begin{array}{l}\text { Severe } \\
\text { preeclampsia }\end{array}$ & $\begin{array}{l}\text { Control } \\
\text { group }\end{array}$ & \multirow[t]{2}{*}{$t$} & \multirow[t]{2}{*}{$\mathbf{P}$} \\
\hline Min-Max & $12.10-120.50$ & $8.20-55.40$ & & \\
\hline $\begin{array}{l}\text { Mean } \pm S \\
\text { D }\end{array}$ & $70.71 \pm 29.06$ & $17.78 \pm 11.05$ & $\begin{array}{l}12.4 \\
27^{*}\end{array}$ & $\begin{array}{l}<0.0 \\
01^{*}\end{array}$ \\
\hline median & 72.0 & 15.55 & & \\
\hline
\end{tabular}

$\mathrm{t}$ : Student t-test, ${ }^{*}$ Statistically significant at $\mathrm{p} \leq 0.05$.

Table 5: Sensitivity, specificity and accuracy for S. endoglin.

\begin{tabular}{|lllllllll|} 
& & Control & Patients & Specificity & Sensitivity & PPV & NPV & Accuracy \\
\hline S.Endoglin & $\leq 24$ & 27 & 6 & 90.0 & 90.0 & 94.74 & 81.82 & 90.0 \\
\hline
\end{tabular}

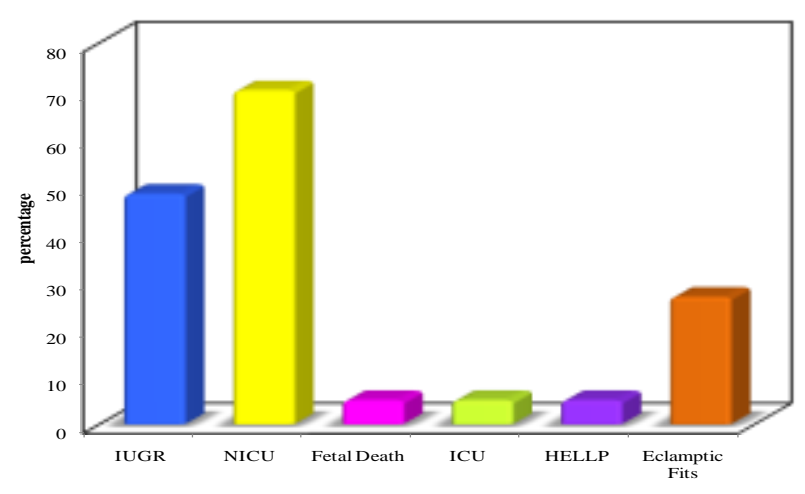

Figure 1: Complications in severe preeclampsia group.

Both groups were subjected to same routine investigations. the group with severe preeclampsia showed significantly higher albumin excretion in urine than the control group $(\mathrm{p}<0.001)$, also showed higher ALT and AST levels than the control group p value was $<0.001$ for each, in the group with severe preeclampsia the platelet count was significantly lower than the control group $(\mathrm{p}<0.001)$, both serum uric acid and serum creatinine were significantly higher in the group with severe preeclampsia than the control group $(\mathrm{p}<0.001)$.

Obstetric ultrasound and Doppler ultrasound was done for both groups, the estimated fetal weight (EFW) and the amniotic fluid index (AFI) were significantly lower in the severe preeclampsia group than the control group $(\mathrm{P}<0.001)$, uterine artery diastolic notch was present in $63.3 \%$ women with severe preeclampsia but was absent in all pregnant women in the control group $(\mathrm{P}<0.001)$, both the pulsatility index and the resistance index were significantly higher in the severe preeclamptic group than the control group $(\mathrm{P}<0.001)$ for each, the $\mathrm{S} / \mathrm{D}$ ratio in the umbilical artery was significantly higher in the severe preeclamptic group than the control group $(\mathrm{P}<0.001)$.

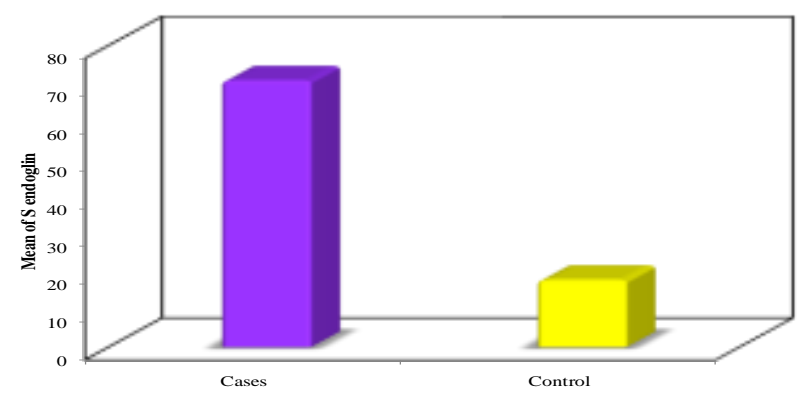

Figure 2: Mean level of soluble endoglin in cases with severe preeclampsia and control group.

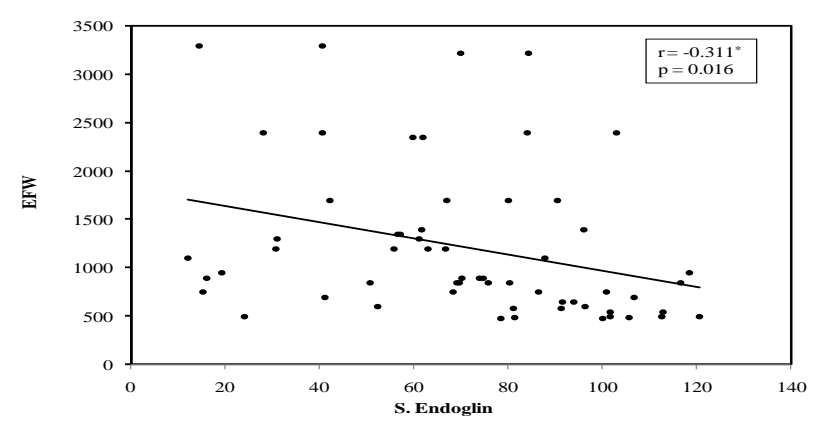

Figure 3: Correlation between S. endoglin with EFW in severe preeclampsia group.

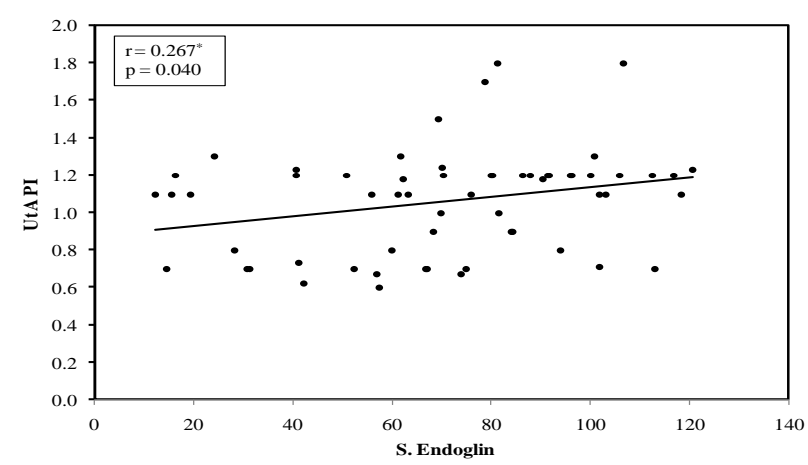

Figure 4: Correlation between S. endoglin with Ut A PI in severe preeclampsia group. 
16 patients in the group with severe preeclampsia suffered eclamptic fits, 3 patients suffered HELLP syndrome and 3 were admitted to the ICU. ${ }^{29}$ patients of the same group suffered intrauterine growth restriction, 42 of the newborn for mothers of that group were admitted to the NICU, unfortunately 3 of the newborn died due to preterm labour IUGR intrauterine growth restriction, NICU neonatal intensive care unit, ICU intensive care unit, HELLP (hemolysis, elevated liver enzymes, low platelet count).

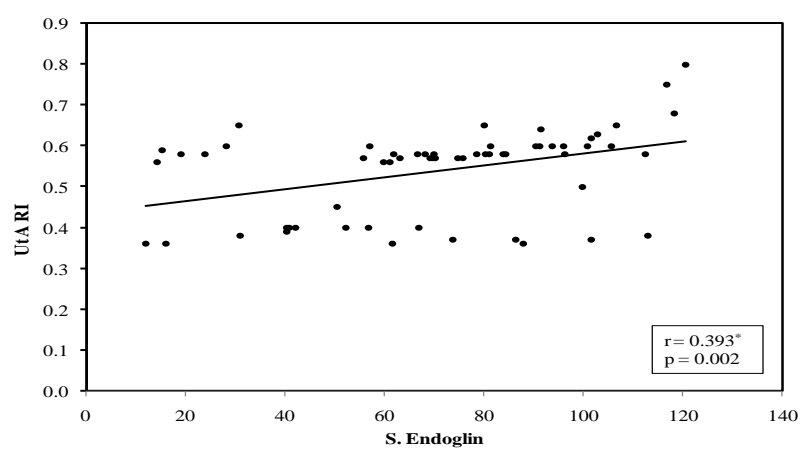

Figure 5: Correlation between S. endoglin with Ut A $\mathrm{RI}$ in sever preeclampsia group.

The two studied group were compared according to serum level of soluble endoglin .In the control group soluble endoglin ranged from $8.20-55.50 \mathrm{ng} / \mathrm{ml}$ the mean level was $17.8 \mathrm{ng} / \mathrm{ml}$, in women with severe preeclampsia soluble endoglin ranged from $12.1-120.5 \mathrm{ng} / \mathrm{ml}$ the mean level was $70.71 \mathrm{ng} / \mathrm{ml}$.

Positive correlation was found between serum level of soluble endoglin and uterine artey PI and uterine artery RI, the higher the seum level of soluble endoglin the higher the uterine artery pulsatility and resistance index. Negative correlation was found between serum level of soluble endoglin and estimated fetal weight, the higher the level of soluble endoglin.

The serum soluble endoglin level of $24 \mathrm{ng} / \mathrm{ml}$ had the best sensitivity and specificity with the highest positive predictive value and lowest negative predictive value.

\section{DISCUSSION}

There was statistically significant difference between group A and group B according to gestational age, systolic blood pressure, diastolic blood pressure, high albuminuria, elevated level of liver enzymes, low platelet count, high uric acid and high serum creatinine $(\mathrm{p}<0.001)$.

On the other hand, there was no statistically significant difference between group A and group B according to the maternal age and high parity.

Serum levels of sEng were significantly elevated in preeclamptic women and levels of sEng correlated strongly with severity of the disease process. Thus, measurement of sEng in the maternal circulation may be a useful diagnostic and screening tool for preeclampsia and would have significant impact in current obstetrical care by reducing preeclampsia-induced morbidity and mortality. $^{24}$

We found statistically significant correlation between serum soluble endoglin and severe preeclampsia which mean soluble endoglin may be used as marker for prediction of severe preeclampsia $(\mathrm{p}<0.001)$.

This correlation is explained by the findings of Venkatesha et al who demonstrated that soluble endoglin acts by antagonizing an angiogenic molecule known as transforming growth factor beta-1, which is important in mediating nitric oxide-dependent vasodilatation and in keeping the lining of blood vessels healthy ${ }^{25}$ Therefore, excess secretion of soluble endoglin leads to severe vasoconstriction, with resulting hypertension, and leakage of proteins into the tissues and urine. ${ }^{26,27}$

Experimental evidence further supports the contribution of soluble endoglin to the pathogenesis of preeclampsia. Venkatesha et al also reported that exogenous soluble endoglin administration in pregnant rats leads to severe preeclampsia, including the HELLP syndrome and restriction of fetal growth. They stated that soluble endoglin increased the likelihood of HELLP syndrome in both the rat model and human pre-eclampsia. ${ }^{28}$

In our study statistically significant difference was found between group A and group B according to the estimated fetal weight, amniotic fluid index and the Doppler flowmetry of the uterine artery $(\mathrm{p}<0.001)$, significant difference was also found between both groups according to the umbilical artery Doppler flowmetry.

In agreement with our study Dehghani-firouzabadi Razieh et al studied the Uterine Artery Doppler Sonography in Predicting Preeclampsia and IUGR at 1416 Week Gestation they concluded that The uterine artery RI at 14-16 weeks was significantly higher in 27 women subsequently developed preeclampsia (mean $\mathrm{RI}=0.7526 \pm 0.039)$ than in 429 pregnancies with a normal outcomes (mean RI=0.6440 $\pm 0.059, \mathrm{p}=0.001)^{29}$

In Dehghani-firouzabadi Razieh study the uterine artery RI also was significantly higher in 36 women developed IUGR (RI=0.7244 \pm 0.047 ) compared with 420 women with normal pregnancies ( $\mathrm{RI}=0.6505 \pm 0.060$, $\mathrm{P}=0.001)$.This confirmed the value of one-stage screening of preeclampsia and IUGR at 14-16 weeks using Doppler sonography of uterine arteries to screen the high risk women. $^{29}$

In agreement with our study kofinas et al studied the uterine and umbilical artery flow velocity waveform analysis in pregnancies complicated by chronic hypertension or preeclampsia. 
It stated that abnormal umbilical artery $\mathrm{S} / \mathrm{D}$ ratio in preeclamptic patients associated with poor pregnancy outcome regarding incidence of IUGR, cesarean section rate, proteinuria, birth weight, mean arterial blood pressure, gestational age at delivery, perinatal morbidity and mortality, and APGAR score. The differences in these factors between the group with normal and the group with abnormal umbilical artery S/D ratio were highly significant. ${ }^{30}$

In our study 29 patients suffered Intrauterine growth restriction (IUGR) represented $48.3 \%$ of the group of severe preeclampsia, 42 of the newborn were admitted to the Neonatal intensive care unit (NICU) representing $70 \%$ of cases with severe preeclampsia but that's affected by the fact that most of severe preeclamptic pregnant ladies were delivered prematurely, 3 of the newborn was born as still birth representing $5 \%$ of the newborn, 3 patients among the selected cases with sever preeclampsia was admitted to the intensive care unit (ICU) representing 5\% of cases, 3 patients among the selected cases with sever preeclampsia suffered HELLP syndrome representing 5\% of cases and 16 patients among the selected cases with severe preeclampsia suffered eclamptic fits representing $26.7 \%$ of cases .

Duphan et al study showed that seven patients of preeclampsia group had eclampsia, 6 had ascites, 3 each had acute renal failure and HELLP syndrome while 2 mothers died. The only maternal complication observed in the neonates, 35 from the preeclampsia group, among required transfer to neonatal intensive care unit (NICU). Twenty three of these were premature and 3 of them expired within a week due to sequelae of prematurity. ${ }^{31}$

As detailed in table 4, significant correlation was found between severe preeclampsia and high level soluble endoglin. The mean level was $17.8 \mathrm{ng} / \mathrm{ml}$ in the control group while it was $70.71 \mathrm{ng} / \mathrm{ml}$ in the sever preeclamptic patients group ( $\mathrm{p}$ value was $<0.001$ ).

In agreement with our study Slahuddin et al reported a significantly higher mean soluble endoglin level in preeclampsia $(69.2 \pm 42.5 \mathrm{ng} / \mathrm{ml})$ than in normotensive pregnant women $(15.5 \pm 6.9 \mathrm{ng} / \mathrm{ml} ; \mathrm{p}=0.01){ }^{32}$

Furthermore, Ham Bak Lee et al stated that the mean serum level of sEng was significantly higher in women with preeclampsia than the control group $(67.7 \pm 36.3$ $\mathrm{ng} / \mathrm{mL}$ vs. $13.7 \pm 8.9 \mathrm{ng} / \mathrm{mL}, \mathrm{P}<0.01){ }^{33}$

In our study ROC curve was plotted for Soluble endoglin (Figure 15), the sesnitivity,specifity, positive predictive value (PPV), negative predictive value (NPV) and area under the ROC curve (AUC) for women with preeclampsia was $90 \%, 90 \%, 94.74 \%, 81.82 \%$ and 0.984 respectively the accuracy was $90 \%$, the cut off value was $24 \mathrm{ng} / \mathrm{ml}$.
Gaber et al at studied Soluble Endoglin as a new marker for prediction of preeclampsia in early pregnancy according to the ROC curve they concluded that sEng has the ability to differentiate preeclamptics from normal pregnancies. It showed an AUC of 0.962. At a cut-off value of $7 \mathrm{ng} / \mathrm{ml}$, the sensitivity was $94.4 \%$, specificity was $87.5 \%$ and accuracy was $89.5 \% .^{34}$

Ham Bak Lee et al at used the ROC curve For sEng, the serum level of $21.1 \mathrm{ng} / \mathrm{mL}$, had best sensitivity and specificity with PPV and NPV (90\%, 83\%, 84\%, and $89 \%$, respectively) in differentiating women with preeclampsia from those with normal pregnancy. The area under the ROC curve was $0.9244^{33}$

Chaiworapongsa $\mathrm{T}$ et al at studied Plasma soluble endoglin concentration in preeclampsia is associated with an increased impedance to flow in the maternal and fetal circulations they found that Among patients with preeclampsia, those with abnormal uterine artery and umbilical artery Doppler velocimetry had the highest median plasma concentration of sEng compared with any other group ( $\mathrm{P}<0.001$, Kruskal-Wallis test). Women with preeclampsia with normal Doppler velocimetry in both vessels had the lowest median plasma concentration of sEng, they concluded that Abnormalities of impedance to blood flow in the UtA and UA are associated with an excess of sEng in the circulation of mothers with PE. These findings suggest that the 'antiangiogenic state' in $\mathrm{PE}$ is partially reflected in abnormalities of Doppler velocimetry. ${ }^{35}$

Tobinaga CM et al at studied Angiogenic factors and uterine Doppler velocimetry in early and late-onset preeclampsia and found that Concentrations of soluble fms-like tyrosine kinase-1 and soluble endoglin were significantly higher in preeclamptic than control women ( $\mathrm{p}<0.0001$ and $\mathrm{p}<0.0001$, respectively), especially in those with early-onset $\left(<34\right.$ weeks) preeclampsia. $^{36}$

These two anti-angiogenic mediators were significantly correlated with increased uterine artery Doppler in the preeclamptic women, they concluded that Preeclamptic patients have increased soluble FMS-like tyrosine kinase1 and soluble endoglin serum levels and this increase is directly correlated with uterine artery resistance, especially in those with early-onset preeclampsia.

From our study, it is evident that serum endoglin rises during normal as well as preeclamptic pregnancy and that the rise in preeclampsia is much higher, the rise in endoglin levels may occur as early as the irst trimester in pregnancies which later develop preeclampsia.

Hence, used alone or in combination with uterine artery doppler flowmetry, the measurement of soluble serum endoglin has the potential for use as a predictive clinical test for preeclampsia risk assessment and could potentially improve the outcome of pregnancy. 
Funding: No funding sources

Conflict of interest: None declared

Ethical approval: The study was approved by the Institutional Ethics Committee

\section{REFERENCES}

1. Sibai B, Dekker G, Kupferminc M. Pre-eclampsia. Lancet. 2005;365:785-99.

2. Ghulmiyyah L, Sibai B. Maternal mortality from preeclampsia/eclampsia. Seminars in Perinatology 2012; 36(1):56-9.

3. WHO Recommendations for prevention and treatment of preeclampsia and eclampsia, WHO Department of Maternal and Child Health, Geneva, Switzerland. World Health Organization (WHO). 2011;38.

4. Irgens HU, Reisaeter L, Irgens LM, Lie RT. Longterm mortality of mothers and fathers after preeclampsia: population based cohort study. BMJ. 2001;323:1213-7.

5. Roberts JM, Taylor RN, Musci TJ, Rodgers GM, Hubel CA, McLaughlin MK. Preeclampsia: an endothelial cell disorder. Am J Obstet Gynecol. 1989;161:1200-4.

6. Chambers JC, Fusi L, Malik IS, Haskard DO, De Swiet M, Kooner JS. Association of maternal endothelial dysfunction with preeclampsia. JAMA. 2001;285:1607-12.

7. Conrad KP, Benyo DF. Placental cytokines and the pathogenesis of preeclampsia. Am J Reprod Immunol. 1997;37:240-9.

8. Fisher SJ, Roberts JM. Defects in placentation and placental perfusion. In: Chelsey's Hypertensive Disorders in Pregnancy. by Lindheimer MD, Roberts JM, and Cunningham FG. Stanford, CT: Appleton \& Lange. 1999;377-94.

9. Maynard SE, Min JY, Merchan J, Lim KH, Li J, Mondal S, et al. Excess placental soluble fms-like tyrosine kinase 1 (sFlt1) may contribute to endothelial dysfunction, hypertension, and proteinuria in preeclampsia. J Clin Invest. 2003;111:649-58.

10. Lam C, Lim KH, Karumanchi SA. Circulating angiogenic factors in the pathogenesis and prediction of preeclampsia. Hypertension. 2005;46:1077-85.

11. Levine RJ, Lam C, Qian C, Yu KF, Maynard SE, Sachs BP, et al. Soluble endoglin and other circulating antiangiogenic factors in preeclampsia. $\mathrm{N}$ Engl J Med. 2006;355:992-1005.

12. Rana S, Karumanchi SA, Levine RJ, Venkatesha S, Rauh-Hain JA, Tamez H, et al. Sequential changes in antiangiogenic factors in early pregnancy and risk of developing preeclampsia. Hypertension. 2007;50:137-42.

13. Makris A, Thornton C, Thompson J, Thomson S, Martin R, Ogle R et al. Uteroplacental isch- emia results in proteinuric hypertension and elevated sFLT-1. Kidney Int. 2007;71:977-84.
14. Park JE, Chen HH, Winer J, Houck KA, Ferrara N. Placenta growth factor. Potentiation of vascular endothelial growth factor bioactivity, in vitro and in vivo, and high affinity binding to Flt-1 but not to Flk-1/KDR. J Biol Chem. 1994;269:25646-54.

15. Venkatesha S, Toporsian M, Lam C, Hanai J, Mammoto T, Kim YM et al, Soluble endoglin contributes to the pathogenesis of preeclampsia. Nat Med. 2006;12:642-6.

16. Carty DM, Delles C, Dominiczak AF. Nov-el biomarkers for predicting preeclampsia. Trends Cardiovasc Med. 2008;18:186-94.

17. Levine RJ, Lam C, Qian C, Yu KF. Soluble endoglin and other circulating antiangiogenic factors in preeclampsia. N Engl J Med. 2006;355:992-1005.

18. Venkatesha S, Toporsian M, Lam C. Soluble endoglin contributes to the pathogenesis of preeclampsia. Nat Med. 2006;12:642-9.

19. Dallas NA, Samuel S, Xia L. Endoglin (CD105): a marker of tumor vasculature and potential target for therapy. Clin Cancer Res. 2008;14:1931-7.

20. Toporsian M, Gros R, Kabir MG. A role for endoglin in coupling eNOS activity and regulating vascular tone revealed in hereditary hemorrhagic telangiectasia. Circ Res. 2005;96:684-92.

21. American College of Obstetricians and Gynecologists (ACOG) Committee on Obstetric Practice: ACOG practice bulletin. Diagnosis and management of preeclampsia and eclampsia. sInt $\mathrm{J}$ Gynecol Obtet. 2002;77:67-75.

22. Kotz S, Balakrishnan N, Read CB, Vidakovic B. Encyclopedia of statistical sciences. $2^{\text {nd }}$ ed. Hoboken, N.J: Wiley-Interscience; 2006.

23. Kirkpatrick LA, Feeney BC. A simple guide to IBM SPSS statistics for version 20.0. Student ed. Belmont, Calif. Wadsworth, Cengage Learning; 2013.

24. Levine RJ, Maynard SE, Qian C, Lim KH, Lucinda J, Yu KF. Circulating angiogenic factors and the risk of preeclampsia. N Engl J Med. 2004:350:672-83.

25. Dugas G, Fuller J, Singh S, Watson J. Pheochromocytoma and pregnancy: a case report and review of anesthetic management. Can J Anaesth. 2004;51:134-8.

26. Venkatesha S, Toporsian M, Lam C. Soluble endoglin contributes to the pathogenesis of preeclampsia. Nat Med. 2006;12:642-9.

27. Masuyama H, Nakatsukasa $H$, Takamoto $N$. Correlation between soluble endoglin, vascular endothelial growth factor receptor-1, and adipocytokines in pre-eclampsia. J Clin Endocrinol Metab. 2009;92:2672-9.

28. Hirashima C, Ohkuchi A, Arai F. Establishing reference values for both total soluble fms-like tyrosine kinase 1 and free placental growth factor in pregnant women. Hypertens Res. 2009;28:727-32.

29. Razieh DF, Mahdyeh M, Saedeh A, Reza NM. Uterine Artery Doppler Sonography in Predicting Preeclampsia and IUGR at 14-16. WASJ. 2013;22(2):197-201. 
30. Kofinas AD, Penry M, Nelson LH, Meis PJ, Swain M. Flow velocity waveform analysis. Southeren medical journal. 1990;83(2):150-5.

31. Duhan N, Sharma D, Garg N, Dahiya K, Sirohiwal D. Comparative evaluation of serum soluble endoglin level in preeclampsia and normotensive pregnant women. J Physiol Pathophysiol. 2011;2(4):47-51.

32. Slahuddin S, Lee Y, Vadnais M, Sachs BP, Karumanchi SA, Lim KH. Diagnostic utility of soluble fms-like tyrosine kinase 1 and soluble endoglin in hypertensive diseases of pregnancy. Am J Obstet Gynecol. 2007;197:28-9.

33. Lee HB, Kil KC, Nam SY, Shin JE, Cheon YJ, Lee Y. Clinical usefulness of soluble fms-like tyrosine kinase 1, soluble endoglin and placental growth factor in korean women with preeclampsia Korean $\mathrm{J}$ Obstet Gynecol. 2011;54(5):229-35.
34. K. Gaber, Hamdyb EC, Hanafy A. Soluble Endoglin as a new marker for prediction of pre-eclampsia in early pregnancy Middle East Fertility Society Journal. 2010;15:42-6.

35. Chaiworapongsa T, Romero R, Kusanovic JP, Mittal P, Kim SK, Gotsch F. Plasma soluble endoglin concentration in pre-eclampsia is associated with an increased impedance to flow in the maternal and fetal circulations. Ultrasound Obstet Gynecol. 2010;35(2):155-62.

36. Tobinaga CM, Torloni MR, Gueuvoghlanian-Silva BY, Pendeloski KPT, Akita PA, Sass N. Angiogenic factors and uterine Doppler velocimetry in early and late-onset preeclampsia. 2014;93(5):469-76.

Cite this article as: Abd El-Dayem TM, Elagwany AS, Khamis MY, Kamha ES, Mohammed Hassan AM. Correlation of serum soluble endoglin to the severity of pre-eclampsia and its effect on the pregnancy outcome. Int $\mathbf{J}$ Reprod Contracept Obstet Gynecol 2016;5:15931600. 